\title{
The relationships of high-fat diet and metabolism of lipophilic vitamins
}

\author{
Jennifer Eastep and Guoxun Chen* \\ Department of Nutrition, University of Tennessee at Knoxville, Knoxville, Tennessee, USA
}

\begin{abstract}
Obesity has become a worldwide problem. One dietary style contributing to this epidemic is the Western diet or high-fat diet (HFD), which is marked by its high-fat content. The effects of HFD on the development of chronic metabolic diseases, such as obesity, have been observed in both human and animal studies. Consumption of HFD generally causes increase of body fat mass with development of symptoms of metabolic diseases such as hyperlipidemia and insulin resistance. Micronutrients are essential for the general health of an individual. Their needs are satisfied by dietary intake. Digestion, absorption and transport of dietary lipophilic vitamins share similar pathways as that of dietary fats. It is still unclear how amounts and compositions of dietary fats affect digestion, absorption and function of lipophilic vitamins and vice versa. A better understanding of the impacts of HFD on homeostasis and functions of lipophilic vitamins may shed light on the development mechanisms of obesity and other metabolic diseases. This review aims to investigate the impact of high-fat feeding on functions of lipophilic vitamins. Research included in this review ranges in publication year 1995 to 2014. It seems that the link between fat metabolism and lipophilic vitamin metabolism has started to be recognized. Additional research projects are warranted.
\end{abstract}

\section{Introduction}

Although we have gradually started to understand roles and usages of vitamins in health and diseases, their contributions to the development of chronic metabolic diseases, such as obesity and type 2 diabetes, are still unclear in the era of overnutrition. Vitamins are defined as organic compounds required in small amounts in the diet to maintain normal functions in the body [1]. They are considered essential nutrients as absence of any of them will result in characteristic signs of a deficiency and may lead to development of diseases. Deficiency and disease development are prevented only by administration or dietary inclusion of the specific organic compounds. Vitamins do not provide energy and are not incorporated in tissue structures. Based on their solubility in aqueous solutions, vitamins are classified as hydrophilic or lipophilic [2]. Fat soluble or lipophilic vitamins are vitamins A (VA), D (VD), E (VE), and K (VK). They can be stored in the body. Historically, those lipophilic vitamins were identified due to the symptoms caused by their deficiencies in animal and human studies such as growth cessation in animals for VA and rickets for VD.

Feeding of a high-fat diet (HFD) has been shown to cause the development of obesity and other metabolic diseases in human and animals. Upon intake, lipophilic vitamins are digested, absorbed and embedded with dietary fat, and transported with chylomicrons through circulation. The major component of dietary fat, triacylglycerol, in chylomicrons is delivered and stored into peripheral tissues due to the action of lipoprotein lipase in the body [2]. It seems to be possible that the amount of dietary fats and their compositions may affect functions, availability and metabolism of lipohilic vitamins, which in turn may affect body health. Here, we try to summarize the current understanding and progress of human and animal research work regarding the effects of HFD intake on functions and availability of lipophilic vitamins. We hope that this work will open novel research areas in nutritional sciences.
The search of current literatures was conducted in the following way. We first searched the online PubMed data base during the time of February to March 2014. Key search terms included HFD, lipophilic vitamins, obesity, and metabolism. All articles selected were published in English. Articles containing research topics of HFD and interactions with lipophilic vitamins in humans or animals were selected. Publication years for the articles range from 1995 to 2014.

\section{Lipophilic vitamins}

The activity of VA (retinol, (2E, 4E, 6E, 8E)-3,7-dimethyl-9(2,6,6-trimethylcyclohex-1-enyl) nona-2,4,6,8-tetraen-1-ol)) was observed to affect the animal somatic growth in 1914 [2], when rats fed a diet made from purified fat extracted from lard or olive oil as the only fat source would lose weight and then die. In contrast, rats receiving certain lipid components from foods such as eggs and butter survived and began to grow again [2]. Later on, its molecular identity as retinol was determined [2]. Even as early as 1816, dogs in nutritional deprivation experiments exhibited corneal ulcers and high mortality [3]. VA activity can be derived from molecules that are capable to be converted into retinol [4]. In the diet, molecules with VA activity are retinol esters (animal sources) and provitamin A carotenoids (plant sources) [5]. In the body, provitamin A carotenoids are cleaved to form retinal, which is then reduced to retinol [5]. The majority of VA physiological activities are mediated by retinoic acid, a metabolite of retinol catabolism [6]. Retinol (an alcohol) is first reversibly oxidized into retinal (an aldehyde), and then irreversibly oxidized into retinoic acid [2]. As an essential micronutrient, VA is needed for vision, cell

Correspondence to: Guoxun Chen, Ph.D., 229 Jessie Harris Building, 1215 West Cumberland Avenue, Knoxville, Tennessee 37996, USA, Tel: 865-974-6257; Fax: 865-974-3491; E-mail: gchen6@utk.edu

Key words: high-fat diet, obesity, body mass, lipophilic vitamins, retinoids

Received: May 15, 2014; Accepted: June 01, 2015; Published: June 04, 2015 
growth, differentiation, etc. [4]. Good sources of dietary provitamin A and VA include pumpkin, carrots, spinach, cantaloupe, liver, eggs and milk [2].

$\mathrm{VD}$ is a group of fat-soluble secosteroids, whose chemical structures were determined in the 1930s [7]. VD discovery came about through observations such as an increase in the prevalence of rickets in populations with decreased exposure to sunlight. It was also observed that children and animals with rickets were cured with sunlight exposure [2,7]. In humans, the most important compounds in this group are $\mathrm{VD}_{3}$ (cholecalciferol) and $\mathrm{VD}_{2}$ (ergocalciferol). Both of these can come from the diet, and $\mathrm{D}_{3}$ can be produced in the skin through exposure to ultra violet light which converts 7-dehydrocholestrol to $\mathrm{D}_{3}[2,7]$. Other forms of $\mathrm{VD}$ include $\mathrm{D}_{1}\left(1: 1\right.$ mixture of $\mathrm{VD}_{2}$ and lumisterol), $\mathrm{D}_{4}$ (22-dihydroergocalciferol) and $\mathrm{D}_{5}$ (sitocalciferol) VD is responsible for enhancing intestinal absorption of calcium, iron, magnesium, phosphate and zinc [7]. Dietary sources of VD include fish and fortified dairy and cereals, but its greatest source comes through ultra violet irradiation in the skin [7] due to few options of food sources containing significant amounts of VD in the forms of cholecalciferol and ergocalciferol [2].

VE was first recognized in 1922 as a reproductive factor [8], in an experiment that described fetal resorption as a symptom in rats due to its dietary deficient [2]. In 1936, a factor from wheat germ was isolated and named $\alpha$-tocopherol [2]. This factor was determined to be required to prevent fetal resorption. When this factor was included in the diet, fetal resorption in the rats ceased. This name was derived from the Greek "tokos" (offspring) and "pherein" (to bear). VE is the collective term for tocopherols and tocotrienols [9]. The sole function of VE in the human body is to act as an antioxidant by preventing the peroxidation of polyunsaturated fatty acids. While there are several forms of VE, $\alpha$-tocopherol remains to be the most potent form observed in the human body [9]. Tocopherols and tocotrienols both consist of a chromanol ring, with a hydroxyl group, and a hydrophobic side chain [1]. This hydroxyl group can donate a hydrogen atom to reduce free radicals. Both of these groups have $\alpha, \beta, \gamma$, and $\delta$ forms, which are determined by the number and position of methyl groups on the chromanol ring. Tocotrienols differ from tocopherols in the presence of double bonds in the hydrophobic side chain [1]. Dietary sources of VE include nuts, seeds and oils [2].

The active molecules for $\mathrm{VK}$ are phylloquinone $\left(\mathrm{K}_{1}\right)$ and menaquinone $\left(\mathrm{K}_{2}\right)$ [10]. The activity of VK was identified in 1929 , when it was observed that chicks consuming a diet that had been extracted with polar solvents developed hemorrhages and that blood collected from these animals clotted slowly [2]. A new fat soluble factor, VK, was proposed in 1935 [2]. In nature, phylloquinone is found in plants and menaquinone is derived from bacteria [10]. $\mathrm{VK}$ is required in human body for post-translational modification of certain proteins required for blood coagulation, and in metabolic pathways in bone and other tissues [11]. Good sources of dietary VK include leafy green vegetables, meat, cheese and eggs [2].

Table 1. Dietary Reference Intake [12]

\begin{tabular}{|l|c|c|c|}
\hline Life Stage Group (Years old) & Vitamin A $(\boldsymbol{\mu g} / \mathbf{d a y})$ & Vitamin D $(\boldsymbol{\mu g} / \mathbf{d a y})$ & Vitamin E (mg/day) \\
\hline Children 1-3 & 300 & 15 & 6 \\
\hline Children 4-8 & 400 & 15 & 7 \\
\hline Males 9-13 & 600 & 15 & 11 \\
\hline Males 14-70 & 900 & 15 & 15 \\
\hline Females 9-13 & 600 & 15 & 60 \\
\hline Females 14-70 & 700 & 15 & 75 \\
\hline
\end{tabular}

*Indicates values for Adequate Intake instead of Recommended Dietary Allowance

Since dietary source is the common route for the uptake of micronutrients, previous human studies have identified dietary reference intakes of the lipophilic vitamins for children, adolescence and adults as shown in Table 1 [12].

\section{HFD and obesity problem}

Obesity has become a worldwide public health concern. For example, with one third of Americans being considered obese, obesity has reached epidemic level in the United States [13]. This is a concern of public health as obesity leads to the development of various metabolic diseases [14], which result in higher mortality rates and higher costs in health care.

One of the dietary styles contributing to the obesity epidemic is the Western Diet (high-fat content), which is characterized by a high intake of red and processed meats, eggs, refined grains and sugars, and energy derived from fat, mainly saturated fatty acids, which can be as high as $35 \%$ of energy $[15,16]$. The Academy of Nutrition and Dietetics recommends that dietary fat provides $20-35 \%$ of energy, emphasizing consumption of $n-3$ polyunsaturated fatty acids while limiting the intake of saturated and trans fatty acids [17]. It has been reported that the fat intake of an average adult is $33 \%$ of energy intake [17]. However, it is important to note that adults may consume more calories than recommended so fat intake would still be higher than recommended. The consequences of consuming a HFD have been documented in human and animal subjects. The HFD pattern has been positively related to body mass index and has been linked to increased risk for type 2 diabetes, coronary heart disease and colon cancer [16]. The intake of a HFD not only increases risk for these diseases, but also reduces functions of the immune system. Additionally, HFD consumption may induce inflammatory pathways in individuals [15].

The detrimental effects of HFD consumption on metabolism have been studied in animals extensively. For example, mice fed a HFD (45\% energy from fat) for 12 weeks developed obesity, hyperinsulinaemia, hyperglycaemia, and hyperleptinaemia [18]. Mice fed a HFD demonstrated significant differences in transcript levels of pancreatic enzymes compared to controls [18]. Sprague-Dawley rats placed on a HFD for 10 weeks demonstrated greater oxidative stress (measured by serum levels of urinary-8-epi-prostaglndin-F2 $\alpha$ and glutathione peroxidase) than controls fed a normal chow diet [19].

Preventing the intake or reducing the absorption of dietary fat has been shown to be beneficial to control the development of metabolic diseases. Reducing fat absorption may alter the levels of lipophilic vitamins in the plasma. Patients with obesity receiving $120 \mathrm{mg}$ three times/day of Orlistat for one year had significant reduction of body mass in association with decrease in levels of VE and $\beta$-carotene, but not VA and VD, compared with those receiving placebo, indicating the essential role of fat absorption in the maintenance of lipophilic vitamin homeostasis [20]. On the other hand, a 12-week treatment of Orlistat (120 mg three times/day) significantly reduced the plasma levels of VA 
and $\mathrm{VE}$ in addition to the reductions of body mass and fat mass in patients with obesity [21].

\section{Current understanding of lipophilic vitamins in HFD feeding conditions}

Dietary intervention in humans can cause the change of plasma levels of lipophilic vitamins. In human subjects of a randomized, doubleblind, placebo-controlled clinical trial, daily intake of 8.8 grams (g) of plant stanol esters for 10 weeks did not change serum levels of VA, VD and $\gamma$-tocopherol, but reduced the levels of total and LDL cholesterol, carotenes and $\alpha$-tocopherol [22]. A $2.6 \mathrm{~g} /$ day dose also significantly reduced LDL, total cholesterol, total triacylglycerol, and carotenes levels, but not VA and VE [23]. In a moderately hypercholesterolemic population, sitostanol ester ( $3 \mathrm{~g} /$ day) for a year significantly reduced the plasma levels of $\alpha$-tocopherol and carotenes in association with the reduction of cholesterol, but not VA and VD levels [24]. On the other hand, short term (2-7 day) intake of HFD in human, did not affect the plasma levels of cholesterol, triacylglycerol, carotenes and VE [25].

\section{Effects of HFD feeding on VA}

As shown in Figure 1, dietary VA comes from retinyl esters (animal sources) and provitamin A carotenoids (plant sources). Pancreatic lipases hydrolyze retinyl esters into retinol and free fatty acids which are absorbed into enterocytes. Retinol is then re-esterified with fatty acids into retinyl esters, which in turn are packaged into chylomicrons with other lipids for delivery to other parts of the body through lymph circulation first and then to the blood circulation. Provitamin A carotenoids are first cleaved to produce retinal which is then reduced into retinol [5].

Retinol is reversibly oxidized into retinal, and retinal is irreversibly oxidized into retinoic acid. Retinoic acid regulates gene expression through activating two nuclear receptor families, retinoic acid receptors (RARs) and retinoid X receptors (RXRs) [5]. Nuclear receptors are ligand-activated transcriptional activators that play essential roles in many physiological processes [26]. The presence of retinoids will regulate the transcription of genes involved in the regulations of these physiological processes [5]. RARs and RXRs form homo- or heterodimers that can bind to retinoic acid response elements (RAREs) in the promoters of their downstream-targeted genes [5]. Retinoic acid can bind to the RAR/RXR heterodimer which will induce a conformational change leading to dissociation of co-repressors from the receptors. Coactivators are then able to bind to the receptor complex which can lead to the regulation of the expression of target genes [2]. Other nuclear receptors such as hepatocyte nuclear factor $4 \alpha$ and chicken ovalbumin upstream transcription factor II have also been suggested to interact with the RARE at the promoter of hepatic glucokinase gene [27]

Retinol metabolite, 11-cis-retinal, plays a critical role in vision. In the eye, 11-cis-retinal is bound to opsin to form rhodopsinin rods. When light enters the eyes, 11-cis-retinal isomerizes to all-trans-retinal and dissociates from opsin. This results in an electric signal along the optic nerve to the brain. A series of enzymatic reactions converts alltrans-retinal back to 11-cis-retinal, which can then rebind to opsin to form rhodopsin to complete the cycle [2].

The roles of VA in high fat feeding have been explored in animal models. Supplementation of additional VA in HFD caused further increase of plasma triacylglycerol levels and expression levels of genes for adipocyte differentiation in rats [28]. On the other hand, in male mice, a supplementation of VA (20 IU/g of diet) in a HFD increased plasma levels of IL-18 and macrophage inflammatory protein-1 (MIP$1 \gamma)$, which occurred in a retinaldehyde dehydrogenase 1-dependent manner [29].

Adverse effects of excessive intake of VA on human and animals have been summarized [30]. Male Sprague-Dawley rats fed on a HFD supplemented with large doses of chitosan have reduction of liver levels of VA and VE, but not VK, demonstrating the effects of dietary components on the lipophilic vitamin statuses in the body [31]. It has been shown that dietary fat and fiber contents affect the VA storage in the liver and conversion of $\beta$-carotene into retinol in Mongolian Gerbils [32]. VA supplementation down-regulates leptin mRNA in adipose tissue in mice and retinoic acid stimulates mRNA expression levels of uncoupling protein 3 in the muscle [33].

\section{Effects of HFD feeding on VD}

Dietary VD, as $\mathrm{D}_{3}$, is incorporated into micelles and enters enterocytes through passive diffusion. After absorption, VD is then packaged in chylomicrons in enterocytes and delivered through lymph circulation. VD synthesized in the skin is transported through the body by VD-binding protein (DBP). Once VD reaches the liver, either through chylomicron remnants removal or DBP, it is hydroxylated to 25-hydroxycholcalciferol $\left(25-\mathrm{D}_{3}\right)[2,7]$.

For VD to become activated, parathyroid hormone stimulates the kidneys to release the enzyme 1-alpha-hydroxylase, which converts 25 $\mathrm{D}_{3}$ to 1,25 -dihydroxycholecalciferol $\left(1,25-\mathrm{D}_{3}\right)$ [34]. DBP binds to 1 , $25-\mathrm{D}_{3}$ so that it is carried to target tissues throughout the body where it can be a ligand for VD receptor (VDR). 1,25- $\mathrm{D}_{3}$ enters cells and binds to VDR causing it to form a heterodimer with RXRs which acts as a transcription factor to regulate gene expression [2].

There is an association of reduced serum $25-\mathrm{D}_{3}$ concentrations with the development of human obesity [35]. However, the effect of VD supplementation on body mass reduction seemed to be uncertain [35]. In children (6-10 year-old), a slight lower value of serum 25-D (drop from $26 \mathrm{ng} / \mathrm{ml}$ of nonobese to $23 \mathrm{ng} / \mathrm{ml}$ of obese) was also associated with obesity [36]. A recent randomized controlled study using seven doses of VD (400-4800 IU/d) in both lean and obese female subjects showed that the rise of blood VD levels is inversely related to the body fat mass, and the normalization of blood VD levels is not associated with reduction of body mass in obese subjects [37]. At this time, the published research investigating the effect of a HFD and VD intake and its plasma level in human subjects seems to be lacking.

Both male and female mice with VD receptor knockout have a lean phenotype and demonstrate resistance to HFD-induced obesity regardless whether they are in the C57BL/6J or CD1 outbred background [38-40]. On the other hand, transgenic expression of human VDR driven by aP2 promoter in adipose tissue resulted in gains of body mass and body fat mass in mice [41]. This phenotype is associated with the elevation of only plasma cholesterol level and changes of expression levels of genes for fuel metabolism in fat tissues and the skeletal muscle [41].

When Sprague-Dawley rats were fed a diet containing low fat (LFD, $10 \%$ energy from fat) or HFD ( $45 \%$ energy from fat) with normal VD or depleted VD (VDD), rats in HFD-VDD group had higher nonalcoholic fatty liver disease (NAFLD) activity Score (NAS) than rats in HFDVD group. On the other hand, rats in LFD groups are protected to the development of NAFLD [42]. The elevation of NAS in rats of HFDVDD group is associated with the change of expression levels of genes 
for hepatic inflammatory and oxidative stress, suggesting the protective role of VD to the development of NAFLD [42]. However, feeding a HFD (40\% energy from fat) in rats for 12 weeks per se did not change serum $1,25-\mathrm{D}_{3}$ level, whereas supplementation of lactose ( $10 \%$ of the diet weight) significantly reduce its level and HFD-induced body mass gain [43].

\section{Effects of HFD feeding on VE}

VE is a collective term for tocopherals and tocotrienols. These molecules differ in the structures of their side chains; tocopherals have a phytyl side chain while tocotrienols have an unsaturated side chain. Only four tocopherols and four tocotrienols meet human VE requirements [2], but in the human body $\alpha$-tocopherol is the most effective one [8].

Within the small intestine, dietary VE is incorporated into micelles. The transfer of VE through the absorptive cells is not well understood, and no intestinal tocopherol transfer protein has been described [2]. In enterocytes, VE is packaged in chylomicrons and delivered to the rest of the body through lymph circulation as the other lipophilic vitamins [44]. While other lipophilic vitamins have their own specific plasma transport proteins, VE is transported nonspecifically in lipoproteins in the plasma [2].

VE is of significant interest because it is a lipid soluble antioxidant [9]. It serves as a radical scavenger that protects polyunsaturated fatty acids in membranes and lipoproteins against lipid oxidation. a-tocopherol scavenges a radical through donating a hydrogen with the resulting $\alpha$-tocopherol radical reacting with ascorbate to return to its reduced state [8].

It has been observed that overweight subjects (body mass index $>27$ ) taking an antioxidant supplement (1g vitamin C/800 IU VE) with a high-fat low-carbohydrate $\operatorname{diet}(63.6 \pm 1.6 \%$ calories as fat $)$ for 8 days had a trend of lower C-reactive protein (30\% reduction compared to baseline). One the other hand,subjects in the placebo group had a trend for higher levels of $\mathrm{C}$-reactive proteinwhich was $50 \%$ increase compared to the baseline level [45].

Several studies have been done in animals to determine the effects of VE in HFD condition. Feeding of VE did not affect the plasma lipid levels in lean or obese mice fed a HFD [46]. The HFD-induced activation of c-Jun $\mathrm{N}$-terminal kinases in rat skeletal muscle was attenuated by including antioxidants including vitamin $\mathrm{C}$ and VE in Wistar rats [47]. Male C57BL/6J mice fed a HFD (70\% energy from fat) with elevated VE content had elevation of $\alpha$-tocopherol in the liver and adipose tissues, which might be protective against lipid peroxidation [48]. Supplementation of VE ( $\alpha$-topopherol) or VD $\left(25-\mathrm{D}_{3}\right)$ in HFD significantly reduced the plasma level of IL-6, but not IL-10, in HFDfed male Swiss mice [49]. Tocotrienol supplementation also reduced damages of feeding high-carbohydrate and HFD to the heart and liver in Wistar rats [50]. A 6-week VE ( $\alpha$-tocopherol) treatment at a dose of $100 \mathrm{mg} / \mathrm{kg}$ daily via oral gavage significantly reduced the memory impairment induced by a high-fat and high-carbohydrate diet in rats, probably through reduction of oxidative stress in the hippocampus [51]. Specific increase of VE content in mitochondria using a mitochondria-targeted VE derivative, MitoVit E (conjugated with triphenylphosphonium), has been shown to reduce hepatic oxidative stress and inhibit fat deposition in mice [52].

When mice were fed a HFD supplemented with VE ( $\alpha$-tocopherol, $0.9 \mathrm{~g} / \mathrm{kg}$ of diet $)$ and $1,25-\mathrm{D}_{3}(0.05 \mathrm{mg} / \mathrm{Kg}$ of diet $)$ for 8 weeks, they had lowered plasma levels of IL-6, indicating reduction of inflammatory response [49]. It was suggested that these two vitamins inhibit IL-6 production from adipocytes [49]. HFD induced obese Sprague-Dawley rats supplemented with $350 \mathrm{mg} / \mathrm{kg}$ diet of alpha-tocopherol acetate exhibited significantly less oxidative stress than the controls fed HFD had, based on serum levels of glutathione peroxidaseactivity [19].

\section{Effects of HFD feeding on VK}

As shown in Figure 1, in the small intestine, dietary VK is incorporated into mixed micelles comprising dietary lipids, bile salts, and products of pancreatic lipases [53]. Dietary VK is then absorbed into enterocytes and incorporated into chylomicrons which will enter lymph circulation for delivery to other parts of the body [53]. Chylomicron remnants are eventually taken by the liver where VK is incorporated into very low-density lipoprotein which re-enters the circulation and can be taken up by osteoblasts [53].

VK is essential in blood clotting and bone formation. Quinone oxidoreductases reduce VK to VK hydroquinone. VK hydroquinone serves as a cofactor for VK gamma-carboxylase, which catalyzes the carboxylation of glutamic acid residues, resulting in its activation in blood clotting and bone formation. A reduced VK molecule is converted to VK epoxide and then converted back to VK by VK epoxide reductase [54]. This reduction and re-oxidation of VK coupled with glutamic acid carboxylation is referred to as the VK cycle [2]. Because VK is recycled in the body, human deficiency of VK is rare [54].

The study investigating the effects of HFD on VK intake in human subjects seems to be lacking. Rats fed a HFD (45\% more energy from fat) rich in corn oil had lower plasma phylloquinone level than those

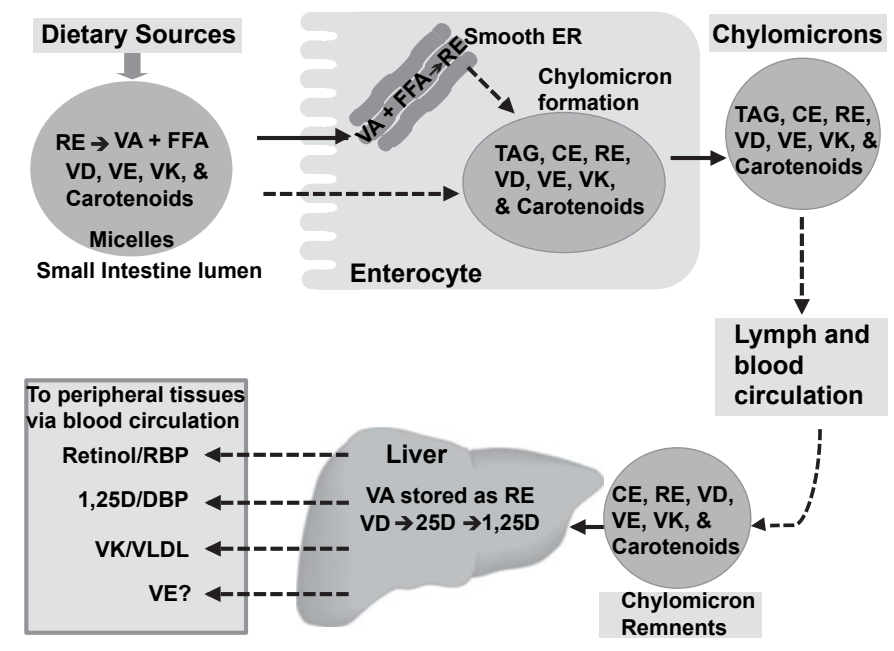

Figure 1. Dietary retinyl esters (REs) are hydrolyzed into vitamin A (VA,retinol) and free fatty acids (FFAs). VA and FFAs are incorporated into micelles along with vitamin D (VD), vitamin $\mathrm{E}(\mathrm{VE})$, vitamin $\mathrm{K}(\mathrm{VK})$, and carotenoids for being taken up by enterocytes of the small intestine. Once in enterocytes, retinol and FFAs are converted into REs in smooth endoplasmic reticulum (ER). REs, triacylglycerol (TAG), VD, VE, VK and carotenoids are incorporated into chylomicrons. Lipophilic vitamins travel through lymph and blood circulations in chylomicrons. Chylomicron remnants reach the liver where VA is stored as REs, and VD is converted to 25-D and then to 1,25-D. From the liver lipophilic vitamins are transported to peripheral tissues, VA is transported as retinol bound to retinol binding protein (RBP), VD is transported as 1, 25-D bound to VD binding protein (DBP), and VK is transported bound to very low density lipoprotein (VLDL). Currently it is unknown if there is a VE transporter carrying it to peripheral tissues.

Abbreviations: CR, chylomicron remnants; DBP, vitamin D binding protein; ER, endoplasmic reticulum; FFA, free fatty acids; RBP, retinol binding protein; RE, retiny ester; TAG, triacylglycerol; VA, vitamin A; VD, vitamin D; VE, vitamin E; VK, vitamin K; VLDL, very low-density lipoprotein. 
fed a low-fat diet although more VK was present in the HFD, indicating the effect of HFD feeding on the plasma level of VK [55]. Additionally, the liver VK level was reduced in rats fed a low-fat diet with fish oil, but not that fed a HFD (already lowered) with fish oil [56].

\section{Conclusion marks and future perspectives}

Based on the research publications summarized here, focuses have been on the protective roles of lipophilic vitamins in the HFD feeding conditions. We have known now that VA status affects plasma lipids levels. While low plasma levels of VD are associated with obesity, supplementation with VD to correct low levels does not appear to alter body mass. VE supplementation in HFD demonstrates a protective effect in obesity via reducing levels of markers of inflammation. On the other hand, how HFD affects homeostasis of lipophilic vitamins remains to be an open question.

Given the essentiality of lipophilic vitamins for the general health of an individual, it is easy to assume that their uptake is helpful in a variety of dietary conditions. On the other hand, their uptakes share the same route as dietary lipids. Mutual effects of dietary lipophilic vitamins and other lipid molecules on each other's digestion, absorption and functions may exist. It is reasonable to assume that transport, storage and metabolism of these lipophilic vitamins alter with the change of diets or metabolic states of a subject or a population. We have shown recently that the expression levels of retinaldehyde dehydrogenase $1 \mathrm{mRNA}$ and protein are elevated in the liver and hepatocytes of Zucker fatty rats, a rat model of hyperphagia and obesity [57]. These results indicate that VA homeostasis changes with the metabolic state of an animal. Despite of the fact that plasma levels of these lipophilic vitamins may not vary significantly between normal and disease states, their intracellular metabolism or modification may change in different organs or tissues. Therefore, additional studies are needed to understand the impacts of dietary components on the homeostasis of lipohilic vitamins.

\section{Acknowledgement}

None of the authors had any conflict of interest to declare.

\section{References}

1. Stipanuk MH (2006) Biological, Physiological, Molecular Aspects of Human Nutrition. Second ed. St. Louis, Missouri: Sauders Elsevier.

2. Modern Nutrition. 11th ed. Baltimore, MD: Lippincott Williams and Wilkins; 2014.

3. Semba RD (2012) On the 'discovery' of vitamin A. Ann Nutr Metab 61: 192-198. [Crossref]

4. Frey SK, Vogel S (2011) Vitamin A metabolism and adipose tissue biology. Nutrients 3: 27-39. [Crossref]

5. Zhao S, Li R, Li Y, Chen W, Zhang Y, et al. (2012) Roles of vitamin A status and retinoids in glucose and fatty acid metabolism. Biochem Cell Biol 90: 142-152. [Crossref]

6. Ross AC (2003) Retinoid production and catabolism: role of diet in regulating retinol esterification and retinoic Acid oxidation. J Nutr 133: 291S-296S. [Crossref]

7. DeLuca HF (2004) Overview of general physiologic features and functions of vitamin D. Am J Clin Nutr 80: 1689S-1696S. [Crossref]

8. Niki E, Traber MG (2012) A history of vitamin E. Ann Nutr Metab 61: 207-212. [Crossref]

9. Traber MG, Atkinson J (2007) Vitamin E, antioxidant and nothing more. Free Radic Biol Med 43: 4-15. [Crossref]

10. Harrington DJ, Soper R, Edwards C, Savidge GF, Hodges SJ, et al. (2005) Determination of the urinary aglycone metabolites of vitamin K by HPLC with redoxmode electrochemical detection. J Lipid Res 46: 1053-1060. [Crossref]
11. Thijssen HH, Vervoort LM, Schurgers LJ, Shearer MJ (2006) Menadione is a metabolite of oral vitamin K. Br J Nutr 95: 260-266. [Crossref]

12. Medeiros DM, Wildman REC (2011) Advanced Human Nutrition. 2nd edn. Sudbury, Massachusetts: Jones and Bartlett Learning.

13. Flegal KM, Carroll MD, Ogden CL, Curtin LR (2010) Prevalence and trends in obesity among US adults, 1999-2008. JAMA 303: 235-241. [Crossref]

14. Haslam DW, James WP (2005) Obesity. Lancet 366: 1197-1209. [Crossref]

15. Myles IA (2014) Fast food fever: reviewing the impacts of the Western diet on immunity. Nutr J 13: 61. [Crossref]

16. Newby PK, Tucker KL (2004) Empirically derived eating patterns using factor or cluster analysis: a review. Nutr Rev 62: 177-203. [Crossref]

17. Vannice G, Rasmussen H (2014) Position of the academy of nutrition and dietetics dietary fatty acids for healthy adults. J Acad Nutr Diet 114: 136-153. [Crossref]

18. Birk RZ, Rubio-Aliaga I, Boekschoten MV, Danino H, Müller M, et al. (2014) Differential regulation of pancreatic digestive enzymes during chronic high-fat dietinduced obesity in C57BL/6J mice. Br J Nutr 112: 154-161. [Crossref]

19. Shen XH, Tang QY, Huang J, Cai W (2010) Vitamin E regulates adipocytokine expression in a rat model of dietary-induced obesity. Exp Biol Med (Maywood) 235: 47-51. [Crossref]

20. Finer N, James WP, Kopelman PG, Lean ME, Williams G (2000) One-year treatment of obesity: a randomized, double-blind, placebo-controlled, multicentre study of orlistat, a gastrointestinal lipase inhibitor. Int J Obes Relat Metab Disord 24: 306-313. [Crossref]

21. Ozcelik O, Ozkan Y, Karatas F, Kelestimur H (2005) Exercise training as an adjunct to orlistat therapy reduces oxidative stress in obese subjects. Tohoku J Exp Med 206 313-318. [Crossref]

22. Gylling H, Hallikainen M, Nissinen MJ, Miettinen TA (2010) The effect of a very high daily plant stanol ester intake on serum lipids, carotenoids, and fat-soluble vitamins. Clinical nutrition (Edinburgh, Scotland) 29: 112-118. [Crossref]

23. Judd JT, Baer DJ, Chen SC, Clevidence BA, Muesing RA, et al. (2002) Plant sterol esters lower plasma lipids and most carotenoids in mildly hypercholesterolemic adults. Lipids 37: 33-42. [Crossref]

24. Gylling H, Puska P, Vartiainen E, Miettinen TA (1999) Retinol, vitamin D, carotenes and alpha-tocopherol in serum of a moderately hypercholesterolemic population consuming sitostanol ester margarine. Atherosclerosis 145: 279-285. [Crossref]

25. Roodenburg AJ, Leenen R, van het Hof KH, Weststrate JA, Tijburg LB (2000) Amoun of fat in the diet affects bioavailability of lutein esters but not of alpha-carotene, betacarotene, and vitamin E in humans. Am J Clin Nutr 71: 1187-1193. [Crossref]

26. Spiegelman BM, Flier JS (2001) Obesity and the regulation of energy balance. Cell 104: 531-543. [Crossref]

27. Li R, Zhang R, Li Y, Zhu B, Chen W, et al. (2014) A RARE of hepatic Gck promoter interacts with RAR $\alpha$, HNF $4 \alpha$ and COUP-TFII that affect retinoic acid- and insulininduced Gck expression. J Nutr Biochem 25: 964-976. [Crossref]

28. Redonnet A, Ferrand C, Bairras C, Higueret P, Noël-Suberville C, et al. (2008) Synergic effect of vitamin A and high-fat diet in adipose tissue development and nuclear receptor expression in young rats. Br J Nutr 100: 722-730. [Crossref]

29. Gushchina LV, Yasmeen R, Ziouzenkova O (2013) Moderate vitamin A supplementation in obese mice regulates tissue factor and cytokine production in a sexspecific manner. Arch Biochem Biophys 539: 239-247. [Crossref]

30. Hathcock JN, Hattan DG, Jenkins MY, McDonald JT, Sundaresan PR, et al. (1990) Evaluation of vitamin A toxicity. Am J Clin Nutr 52: 183-202. [Crossref]

31. Deuchi K, Kanauchi O, Shizukuishi M, Kobayashi E (1995) Continuous and massive intake of chitosan affects mineral and fat-soluble vitamin status in rats fed on a high-fat diet. Biosci Biotechnol Biochem 59: 1211-1216. [Crossref]

32. Deming DM, Boileau AC, Lee CM, Erdman JW Jr (2000) Amount of dietary fat and type of soluble fiber independently modulate postabsorptive conversion of betacarotene to vitamin A in mongolian gerbils. J Nutr 130: 2789-2796. [Crossref]

33. Felipe F, Bonet ML, Ribot J, Palou A (2003) Up-regulation of muscle uncoupling protein 3 gene expression in mice following high fat diet, dietary vitamin A supplementation and acute retinoic acid-treatment. Int J Obes Relat Metab Disord 27: 60-69. [Crossref]

34. Bouillon R, Carmeliet G, Verlinden L, van Etten E, Verstuyf A, et al. (2008) Vitamin D and human health: lessons from vitamin D receptor null mice. Endocr Rev 29: 726776. [Crossref] 
35. Vanlint S (2013) Vitamin D and obesity. Nutrients 5: 949-956. [Crossref]

36. Elizondo-Montemayor L, Ugalde-Casas PA, Serrano-Gonzalez M, Cuello-Garcia CA, Borbolla-Escoboza JR (2010) Serum 25-hydroxyvitamin d concentration, life factors and obesity in Mexican children. Obesity (Silver Spring, Md.) 18: 1805-1811.

37. Gallagher JC, Yalamanchili V, Smith LM (2013) The effect of vitamin D supplementation on serum 25(OH)D in thin and obese women. J Steroid Biochem Mol Biol 136: 195-200. [Crossref]

38. Narvaez CJ, Matthews D, Broun E, Chan M, Welsh J (2009) Lean phenotype and resistance to diet-induced obesity in vitamin $\mathrm{D}$ receptor knockout mice correlates with induction of uncoupling protein-1 in white adipose tissue. Endocrinology 150: 651661. [Crossref]

39. Weber K, Erben RG (2013) Differences in triglyceride and cholesterol metabolism and resistance to obesity in male and female vitamin D receptor knockout mice. $J$ Anim Physiol Anim Nutr (Berl) 97: 675-683. [Crossref]

40. Wong KE, Szeto FL, Zhang W, Ye H, Kong J, et al. (2009) Involvement of the vitamin D receptor in energy metabolism: regulation of uncoupling proteins. Am J Physiol Endocrinol Metab 296: E820-828. [Crossref]

41. Wong KE, Kong J, Zhang W, Szeto FL, Ye H, et al. (2011) Targeted expression of human vitamin D receptor in adipocytes decreases energy expenditure and induces obesity in mice. $J$ Biol Chem 286: 33804-33810. [Crossref]

42. Roth CL, Elfers CT, Figlewicz DP, Melhorn SJ, Morton GJ, et al. (2012) Vitamin $\mathrm{D}$ deficiency in obese rats exacerbates nonalcoholic fatty liver disease and increases hepatic resistin and Toll-like receptor activation. Hepatology 55: 1103-1111. [Crossref]

43. Goseki-Sone M, Maruyama R, Sogabe N, Hosoi T (2007) Effects of dietary lactose on long-term high-fat-diet-induced obesity in rats. Obesity (Silver Spring) 15: 2605-2613. [Crossref]

44. Borel P, Pasquier B, Armand M, Tyssandier V, Grolier P, et al. (2001) Processing of vitamin $\mathrm{A}$ and $\mathrm{E}$ in the human gastrointestinal tract. Am J Physiol Gastrointest Liver Physiol 280: G95-95G103. [Crossref]

45. Peairs AT, Rankin JW (2008) Inflammatory response to a high-fat, low-carbohydrate weight loss diet: effect of antioxidants. Obesity (Silver Spring) 16: 1573-1578. [Crossref]

46. Hasty AH, Gruen ML, Terry ES, Surmi BK, Atkinson RD, et al. (2007) Effects of vitamin $\mathrm{E}$ on oxidative stress and atherosclerosis in an obese hyperlipidemic mouse model. J Nutr Biochem 18: 127-133. [Crossref]
47. Vinayagamoorthi R, Bobby Z, Sridhar MG (2008) Antioxidants preserve redox balance and inhibit c-Jun-N-terminal kinase pathway while improving insulin signaling in fatfed rats: evidence for the role of oxidative stress on IRS-1 serine phosphorylation and insulin resistance. J Endocrinol 197: 287-296. [Crossref]

48. Sohet FM, Neyrinck AM, Dewulf EM, Bindels LB, Portois L, et al. (2009) Lipid peroxidation is not a prerequisite for the development of obesity and diabetes in highfat-fed mice. Br J Nutr 102: 462-469. [Crossref]

49. Lira FS, Rosa JC, Cunha CA, Ribeiro EB, do Nascimento CO, et al. (2011) Supplementing alpha-tocopherol (vitamin E) and vitamin D3 in high fat diet decrease IL-6 production in murine epididymal adipose tissue and 3T3-L1 adipocytes following LPS stimulation. Lipids Health Dis 10: 37. [Crossref]

50. Wong WY, Poudyal H, Ward LC, Brown L (2012) Tocotrienols reverse cardiovascular metabolic and liver changes in high carbohydrate, high fat diet-fed rats. Nutrients 4 : 1527-1541. [Crossref]

51. Alzoubi KH, Khabour OF, Salah HA, Hasan Z (2013) Vitamin E prevents high-fat high-carbohydrates diet-induced memory impairment: the role of oxidative stress. Physiol Behav 119: 72-78. [Crossref]

52. Mao G, Kraus GA, Kim I, Spurlock ME, Bailey TB, et al. (2010) A mitochondriatargeted vitamin $\mathrm{E}$ derivative decreases hepatic oxidative stress and inhibits fat deposition in mice. J Nutr 140: 1425-1431. [Crossref]

53. Shearer MJ, Fu X, Booth SL (2012) Vitamin K nutrition, metabolism, and requirements: current concepts and future research. Adv Nutr 3: 182-195. [Crossref]

54. Gong X, Gutala R, Jaiswal AK (2008) Quinone oxidoreductases and vitamin K metabolism. Vitam Horm 78: 85-101. [Crossref]

55. Schurgers LJ, Vermeer C (2001) Corn oil-induced decrease in arterial thrombosis tendency may be related to altered plasma vitamin K transport. J Lipid Res 42: 11201124. [Crossref]

56. Nieuwenhuys CM, Feijge MA, Vermeer C, Hennissen AH, Beguin S, et al. (2001) Vitamin K-dependent and vitamin K-independent hypocoagulant effects of dietary fish oil in rats. Thromb Res 104: 137-147. [Crossref]

57. Li Y, Zhang Y, Li R, Chen W, Howell M, et al. (2012) The hepatic Raldh1 expression is elevated in Zucker fatty rats and its over-expression introduced the retinal-induced Srebp-1c expression in INS-1 cells. PLoS One 7: e45210. [Crossref]

Copyright: (C2015 Eastep J. This is an open-access article distributed under the terms of the Creative Commons Attribution License, which permits unrestricted use, distribution, and reproduction in any medium, provided the original author and source are credited. 